\title{
Collective Thomson scattering diagnostic at Wendelstein 7-X
}

Moseev, D.; Stejner, M.; Stange, T.; Abramovic, I.; Laqua, H. P.; Marsen, S.; Schneider, N.; Braune, H.; Hoefel, U.; Kasparek, W.

Total number of authors:

18

Published in:

Review of Scientific Instruments

Link to article, DOI:

$10.1063 / 1.5050193$

Publication date:

2019

Document Version

Publisher's PDF, also known as Version of record

Link back to DTU Orbit

Citation (APA):

Moseev, D., Stejner, M., Stange, T., Abramovic, I., Laqua, H. P., Marsen, S., Schneider, N., Braune, H., Hoefel, U., Kasparek, W., Korsholm, S. B., Lechte, C., Leipold, F., Nielsen, S. K., Salewski, M., Rasmussen, J., Weißgerber, M., \& Wolf, R. C. (2019). Collective Thomson scattering diagnostic at Wendelstein 7-X. Review of Scientific Instruments, 90(1), [013503]. https://doi.org/10.1063/1.5050193

\section{General rights}

Copyright and moral rights for the publications made accessible in the public portal are retained by the authors and/or other copyright owners and it is a condition of accessing publications that users recognise and abide by the legal requirements associated with these rights.

- Users may download and print one copy of any publication from the public portal for the purpose of private study or research.

- You may not further distribute the material or use it for any profit-making activity or commercial gain

- You may freely distribute the URL identifying the publication in the public portal 


\section{Collective Thomson scattering diagnostic at Wendelstein 7-X}

Cite as: Rev. Sci. Instrum. 90, 013503 (2019); https://doi.org/10.1063/1.5050193

Submitted: 27 July 2018 . Accepted: 29 November 2018. Published Online: 08 January 2019

D. Moseev, M. Stejner, T. Stange, I. Abramovic, H. P. Laqua, S. Marsen, N. Schneider, H. Braune, U. Hoefel (D), W. Kasparek, S. B. Korsholm (D), C. Lechte, F. Leipold, S. K. Nielsen, M. Salewski (D), J. Rasmussen (D), M. Weißgerber, and R. C. Wolf (i)
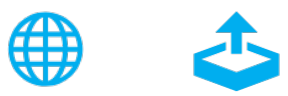

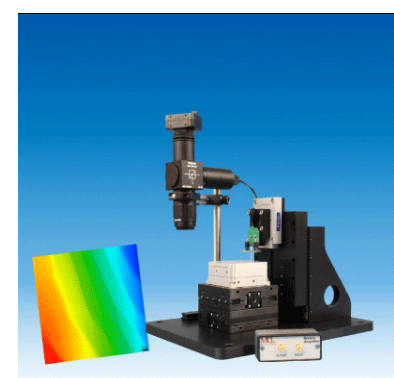

AFM \& NSOM
Nanopositioning Systems

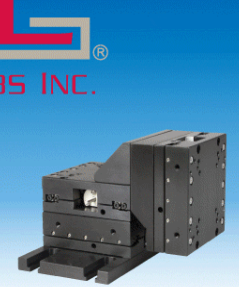

Micropositioning

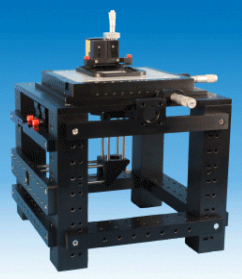

Single Molecule Microscopes 


\title{
Collective Thomson scattering diagnostic at Wendelstein 7-X
}

\author{
Cite as: Rev. Sci. Instrum. 90, 013503 (2019); doi: 10.1063/1.5050193 \\ Submitted: 27 July 2018 - Accepted: 29 November 2018 • \\ Published Online: 8 January 2019
}

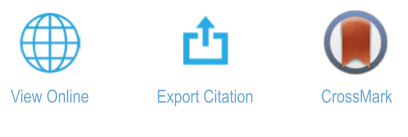

D. Moseev, ${ }^{1, a)}$ M. Stejner, ${ }^{2}$ T. Stange, ${ }^{1}$ I. Abramovic, ${ }^{1,3}$ H. P. Laqua, ${ }^{1}$ S. Marsen, ${ }^{1}$ N. Schneider, ${ }^{1}$ H. Braune,

U. Hoefel, ${ }^{1}$ (D) W. Kasparek, ${ }^{4}$ S. B. Korsholm, ${ }^{2}$ (D C. Lechte, ${ }^{4}$ F. Leipold, ${ }^{2}$ S. K. Nielsen, ${ }^{2}$ M. Salewski, ${ }^{2}$

J. Rasmussen, ${ }^{2}$ (i) M. Weißgerber, ${ }^{1}$ and R. C. Wolf' (i)

\author{
AFFILIATIONS \\ ${ }^{1}$ Max-Planck-Institut für Plasmaphysik, Greifswald and Garching, Germany \\ ${ }^{2}$ Technical University of Denmark, Kongens Lyngby, Denmark \\ ${ }^{3}$ Eindhoven University of Technology, Eindhoven, The Netherlands \\ ${ }^{4}$ University of Stuttgart, Stuttgart, Germany
}

a)Electronic mail: dmitry.moseev@ipp.mpg.de

\begin{abstract}
A Collective Thomson Scattering (CTS) diagnostic is installed at Wendelstein 7-X for ion temperature measurements in the plasma core. The diagnostic utilizes $140 \mathrm{GHz}$ gyrotrons usually used for electron cyclotron resonance heating (ECRH) as a source of probing radiation. The CTS diagnostic uses a quasi-optical transmission line covering a distance of over $40 \mathrm{~m}$. The transmission line is shared between the ECRH system and the CTS diagnostic. Here we elaborate on the design, installation, and alignment of the CTS diagnostic and present the first measurements at Wendelstein 7-X.
\end{abstract}

Published under license by AIP Publishing. https://doi.org/1 0.1063/1.5050193

\section{INTRODUCTION}

The ion temperature $T_{i}$ is a key parameter to describe plasmas in tokamaks and stellarators. It is important for transport studies not to mention the fusion yield. Currently, the impurity (argon) ion temperature in Wendelstein 7-X (W7-X) is measured by X-ray spectroscopy (XICS). ${ }^{1-3}$ It provides lineintegrated measurements which are inverted using a modified Levenberg-Marquardt algorithm into profile measurements. A local ion temperature measurement in the core is important because it provides a constraint for the XICS inversion, which collective Thomson scattering (CTS) is capable of providing.

Here we report on the instrumental aspects of the diagnostic. The diagnostic is inspired by the one installed at ASDEX Upgrade. ${ }^{4-9}$ The microwave-based CTS diagnostic has proven its capability for ion temperature measurements on several tokamaks $^{10,11}$ and stellarators. ${ }^{12,13}$ A CTS diagnostic will also be installed on ITER. ${ }^{14-16}$ CTS measures directly the bulk plasma (i.e., usually deuterium, helium, or hydrogen) temperature rather than the temperature of an impurity. These two temperatures can sometimes be quite different. ${ }^{16}$ Recently, the feasibility of $\mathrm{T}_{i}$ measurements by CTS, having the second harmonic electron-cyclotron resonance in a direct view of the receiver, was demonstrated on ASDEX Upgrade. ${ }^{18,19}$

CTS is scattering of electromagnetic waves off the collective fluctuations in the plasma, and its principles are sketched in Fig. 1. The measurements are performed using a probing beam with the wave vector $\vec{k}^{i}$, which is scattered on fluctuations in the plasma, and a receiver beam with the wave vector $\vec{k}^{s}$ of detectable scattered waves. Salpeter ${ }^{20}$ found that if $k^{\delta} \lambda_{D}$ $<1$, where $k^{\delta}$ is the magnitude of $\vec{k}^{\delta}=\vec{k}^{s}-\vec{k}^{i}$ and $\lambda_{\mathrm{D}}$ is the Debye length, the spectrum of the scattering radiation bears signatures of collective effects in the plasma. The CTS diagnostic measures a spectrum of scattered microwaves. Generally, the spectral shape and magnitude depends on the scattering geometry and many plasma parameters: the ion temperature $\mathrm{T}_{i}$, the electron temperature $\mathrm{T}_{e}$, the electron density $\mathrm{n}_{e}$, the effective charge $Z_{\text {eff }}$, etc. Comprehensive models ${ }^{21}$ exist which allow inference of the plasma parameters by solving an inverse 


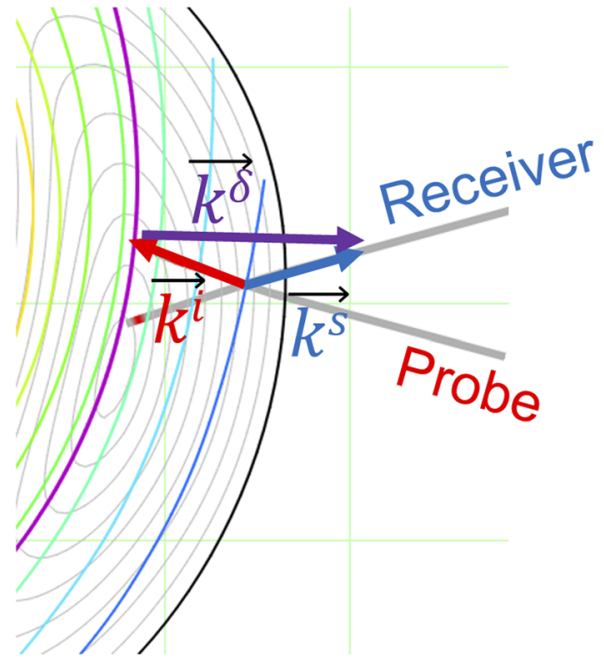

FIG. 1. A sketch illustrating a principle of CTS. $\overrightarrow{k^{i}}$ and $\overrightarrow{k^{s}}$ are the wave vectors of the incident and the received scattered waves, respectively. The fluctuations are measured along $\overrightarrow{k^{\delta}}=\overrightarrow{k^{s}}-\overrightarrow{k^{i}}$. The detected fluctuations are collective if $k^{\delta} \lambda_{D}<1$.

problem. Bayesian inference using the Minerva framework ${ }^{22}$ is employed for $T_{i}$ measurements in $\mathrm{W} 7-\mathrm{X} .{ }^{23}$ Neural network analysis will also be used for the fast evaluation of the ion temperature in $\mathrm{W} 7-\mathrm{X}{ }^{24}$ The sensitivity of the diagnostic to the ion temperature is illustrated by the scattering functions in Fig. 2 which describes the spectrum formation in CTS measurements. We use O-O mode scattering of the probing radiation of $140 \mathrm{GHz}$. The electron temperature is $8 \mathrm{keV}$, and the ion temperatures are $4 \mathrm{keV}$ and $8 \mathrm{keV}$. One can clearly see the influence of ion temperature on the shape of the spectrum.

The design aspects of the CTS diagnostic for W7-X are discussed in Sec. II. Section III addresses the alignment of the

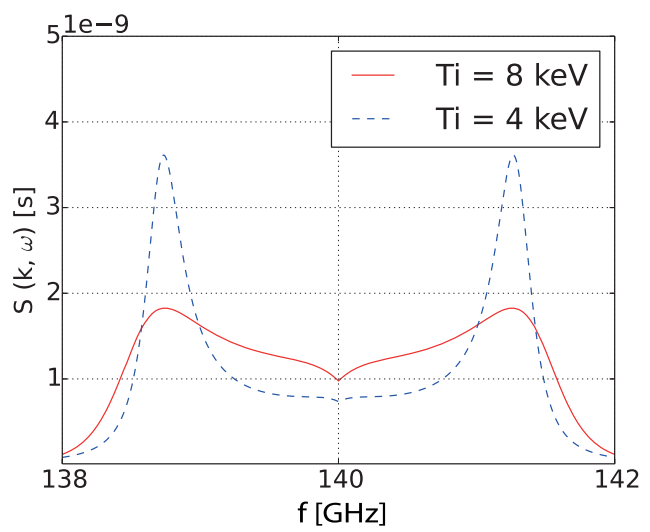

FIG. 2. Two example spectra where the hydrogen ion temperature is varied (4 and $8 \mathrm{keV}$ ), having the other parameters fixed: $T_{e}=8 \mathrm{keV}, B=2.4 \mathrm{~T}, n_{e}=10^{20} \mathrm{~m}^{-3}$, $f_{\text {probe }}=140 \mathrm{GHz}, 0-0$ mode scattering, angle of $\overrightarrow{k \delta}$ to the external magnetic field is $110^{\circ}$, and the scattering angle is $140^{\circ}$. transmission line. The first experimental results from Wendelstein 7-X are presented in Sec. IV. Section V concludes this publication.

\section{DESIGN OF THE CTS DIAGNOSTIC}

The W7-X electron cyclotron resonance heating (ECRH) system consists of ten gyrotrons working at $140 \mathrm{GHz}$, a quasioptical transmission line, and several launchers located in modules 1 and 5 of the stellarator, as schematically shown in Fig. 3. A more detailed description of the ECRH setup is given in Ref. 25. The CTS diagnostic extensively uses the ECRH infrastructure of W7-X. The two gyrotrons A1 and B1 from the ECRH installation are used as sources of the probing radiation for CTS. The pre-installed ECRH launcher mirror F1 is used as a front-end receiver antenna. The number of installed ECRH launchers per module is one more than the number of gyrotrons in the corresponding module. The extra launchers are reserved for future upgrades of the ECRH installation. The main part of the transmission line from the matching optics unit (MOU) at the end of the transmission line to the ECRH tower in module 1 is also shared.

The diagnostic is able to collect scattered microwaves from two different locations in the plasma, namely, from the bean-shaped cross section through the port E10 and from the triangular cross section through the port T10. Both ports are located in module 1 . These cross sections are illustrated in Fig. 4. The ECRH launchers in the E10 port (bean-shaped cross section) are equipped with the mirrors that have $2 \mathrm{D}$ steering capabilities, which allow scattering geometries with a various angle of $\overrightarrow{k^{\delta}}$ to the external magnetic field. The values of this angle is typically in the range from $85^{\circ}$ to $120^{\circ}$ and more precisely depend on the radial location of the overlap volume. The overlap volume cannot be placed in the plasma center because both the probing and the receiver beams are absorbed there. In the triangular cross section, both probing and receiver beams can be steered in one dimension only. Therefore, the variety of scattering geometries is limited and the scattering geometry where the angle of $\overrightarrow{k^{\delta}}$ to the external magnetic field is $90^{\circ}$ is not available. At the same time, in the triangular cross section, it is possible to place an overlap volume in the plasma center.

Due to the topology of the magnetic field, better resolution of $\mathrm{T}_{i}$ measurements in the magnetic flux co-ordinates can be achieved in the triangular cross section. The exact values of achievable resolution depend on the exact scattering geometry and the chosen cross section and vary in the range $\Delta \rho_{t} \approx 0.1-0.5$, where $\rho_{t}$ stands for normalized toroidal flux. The diagnostic utilizes the remote steering launcher (RSL) ${ }^{25,26}$ in the N10 port (module 1) in order to transmit the probing radiation into the triangular cross section. The B1 gyrotron has a possibility to be switched to the remote steering antenna in the triangular cross section (N10 port) in module 1 .

In the bean-shaped cross section, the second harmonic $140 \mathrm{GHz}$ electron cyclotron (EC) resonance surface crosses the plasma through the center from top to bottom. This implies 


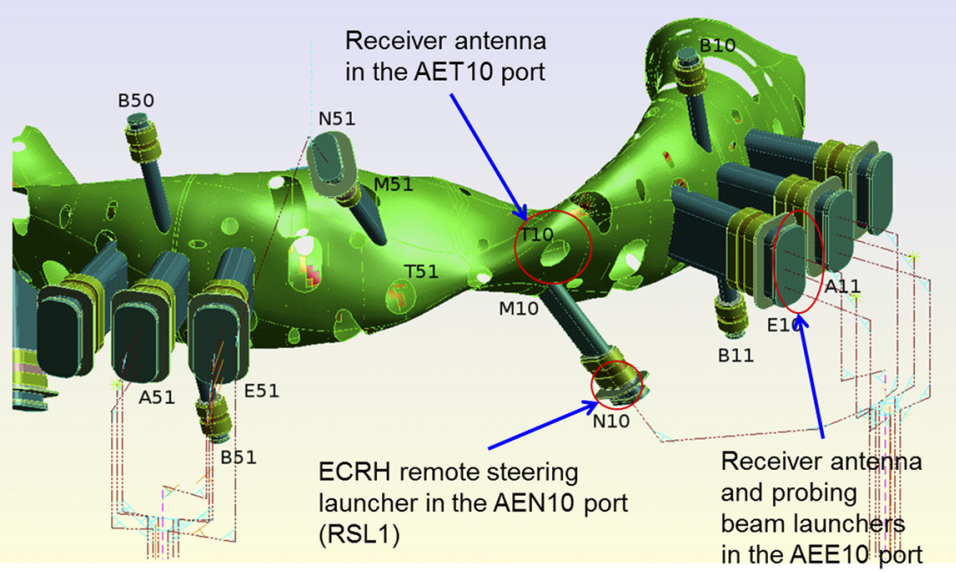

FIG. 3. A CAD overview of a part of the W7-X vessel with the ECRH launchers and CTS receiver antennas. that the probing beam will be absorbed at the plasma center or earlier. Hence, the scattering volume cannot be placed in the very core. The electron cyclotron emission (ECE) background which is measured by the diagnostic is also very high and corresponds to the electron temperature near plasma center, which is in the range of several $\mathrm{keV}$. In the triangular cross section, the receiver beam at its first pass does not cross the resonance surface and one might expect lower levels of the received ECE background radiation. However, reflected ECE enters the receiver in the triangular cross section as well and

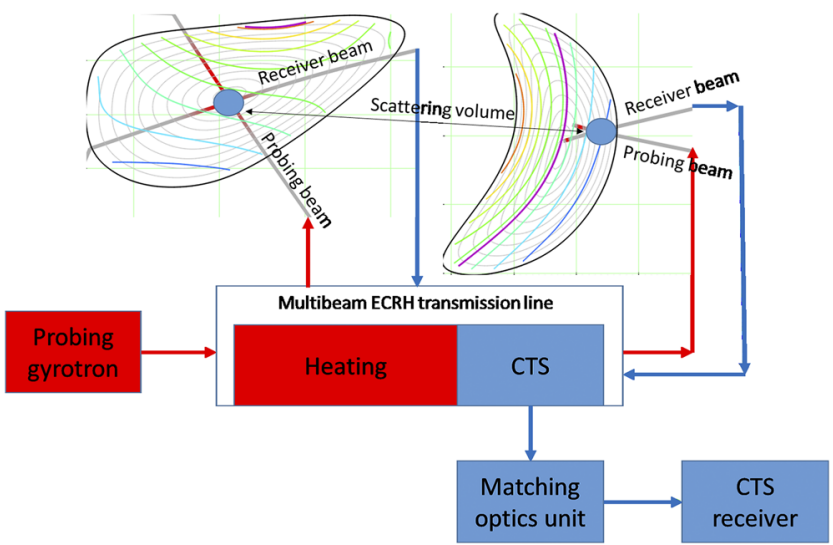

FIG. 4. Diagram of the CTS diagnostic. Two stellarator cross sections are shown where the CTS measurements are performed. On each of the cross sections, the last closed flux surface is indicated (gray meshed surface). The left cross section is a triangular cross section (receiver in the T10 port), and the right cross section is bean-shaped (receiver in the E10 port). Two beams are assigned as a probing beam and as a receiving beam in each cross section. Red coloring along the beam lines in the plasma shows the position of electron cyclotron absorption and emission for $140 \mathrm{GHz}$ probing and receiver beams, respectively. The location where two beams intersect in the plasma is denoted as the origin of the measured scattering radiation. Red arrows indicate the direction of the power flow from the gyrotron to the plasma via the multi-beam quasi-optical ECRH transmission line. The blue arrows show the power flow of the scattering radiation toward the CTS receiver (heterodyne radiometer) via the multi-beam quasi-optical ECRH transmission line and the matching optics unit. the ECE background is only reduced insignificantly. Nonetheless, a clear advantage of the triangular cross section is the accessibility of the plasma center for the $T_{i}$ measurements.

\section{A. Transmission line}

The CTS diagnostic at W7-X uses the standard ECRH system to provide the probing radiation. Here we focus on the transmission of the received radiation from the plasma to the receiver. The receiver is connected via a matching optics unit and a quasi-optical transmission line to the receiver mirrors in module 1 in the triangular and bean-shaped cross sections. An overview of the transmission line is shown in Fig. 5. Switching between the two cross sections is performed by the manually removable mirror in the vicinity of the launcher in the beanshaped cross section, in ECRH tower 1. Switching can be performed whenever there is access to the torus hall. A detailed view of the front-end part of the diagnostic is shown in Fig. 6. A general overview is shown in Fig. 6(a). On the left, one can see the ECRH tower where the last stage of the quasi-optical transmission line, launching optics for ECRH, and receiving optics for CTS (bean-shaped cross section) are located. The removable mirror is shown which serves as a switch between two CTS views. On the same figure, one can see a port plugin for the CTS diagnostic in the triangular cross section. The front-end part of the CTS system in the bean-shaped cross section is shown in Fig. 6(c). The mirrors for CTS and ECRH are identical and have large steering flexibility.

The overview of the modified transmission line is shown in Fig. 5. The locations of the receiving optics are schematically depicted in Fig. 3 and denoted by the name of the ports where the launching and receiving optics are located: E10 [see Figs. 6(c) and 6(b)] for the bean-shaped cross section and N10 - T10 for the launcher and the receiver, respectively, for the triangular cross section; see Fig. 8.

When scattered radiation is collected from the beanshaped cross section, microwaves are transmitted from the front-steering plasma mirror and a fixed mirror in vacuum through the boron nitride window (ECRH vacuum windows 


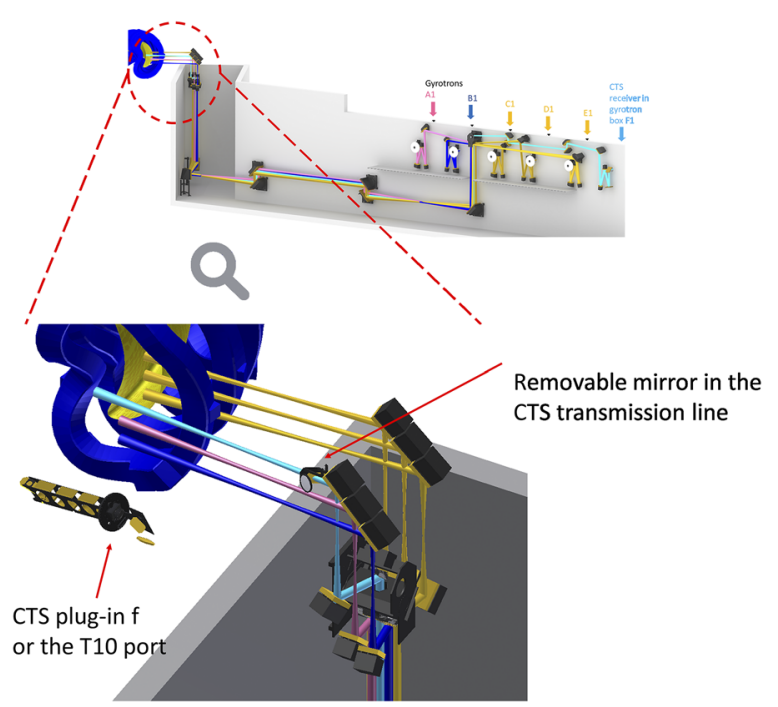

FIG. 5. A detailed representation of the transmission line used by ECRH and CTS Pink and blue lines represent beams from the probing gyrotrons $A 1$ and $B 1$, and yellow beams originate from gyrotrons that can only be used for heating. The received CTS beam is shown in cyan. The lower panel shows a zoomed view of the transmission line after the beam dividing optics (vacuum window and mirrors thereafter are not displayed) with the removable mirror for switching the receiver view to the triangular cross section.

are made of CVD diamonds) to a set of fixed and aligned mirrors which guide radiation to the beam-combining optics. In this configuration, the removable mirror is removed from the transmission line. When scattered microwaves are collected from the triangular cross section, the radiation comes from the port plug-in shown in Fig. 6(a) and the received beam is selected by the steerable mirror at the plug-in located outside of the vacuum vessel. From the removable mirror onward, there is no difference for the beam paths originating from the bean-shaped and triangular cross sections. The beam dividing optics is a set of mirrors where the multi-beam is divided into individual ECRH beams or receiving beams and transmitted to launchers. Optically it is identical to the beamcombining optics, where individual microwave beams are collected for transmission in the multi-beam part of the transmission line; see Fig. 7(a). The terms "combining" and "dividing" were introduced with respect to the ECRH beams which travel from gyrotrons to the plasma. We will stick to these names even for the received CTS radiation propagates in the opposite direction. The need of the multi-beam section is to simplify the transmission line and save the effort during alignment. After passing the beam dividing optics, the received CTS radiation shares the same multi-beam mirrors with the gyrotrons in module 1 , including the probing beam. This is a unique feature of the design of the W7-X CTS system as in no other CTS diagnostic do the receiver and the probing beams share the same mirrors simultaneously. Although the intensities of the beams differ by 120-140 dB, it imposes no practical difficulties. The multi-beam mirror and its dimensions are shown in Fig. 7(b). At the beam combining optics, the

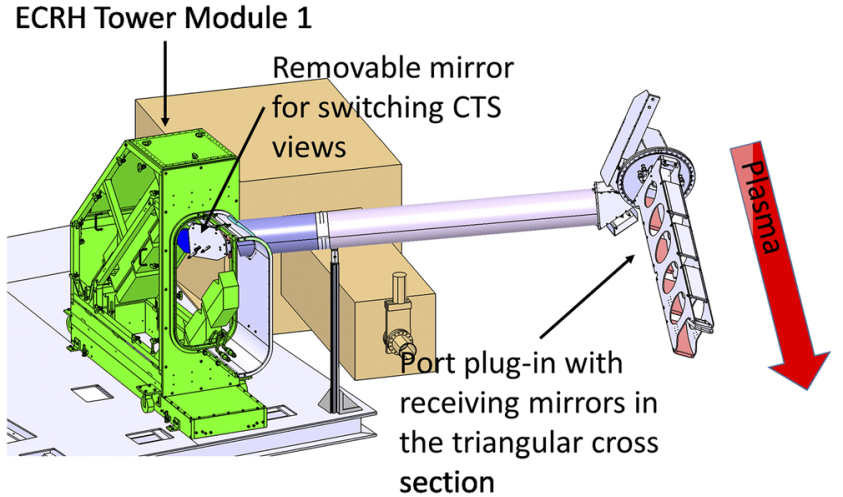

(a)

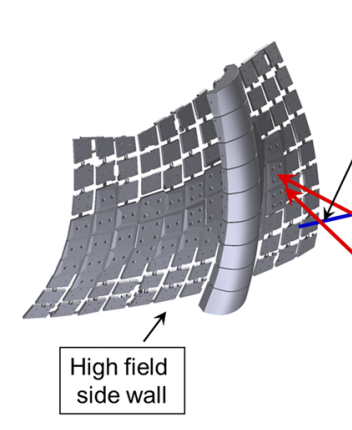

(b)

Scattering regions inside the plasma with the beam width $\mathrm{w} \approx 40 \mathrm{~mm}$

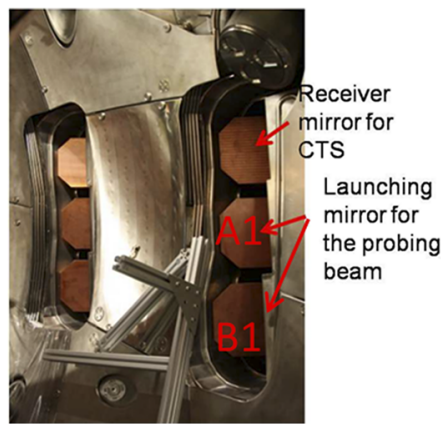

(c)

FIG. 6. CTS infrastructure in the W7-X torus hall. (a) Overview of the CTS installation in the torus hall. The CTS receiver mirrors are located in the ECRH tower in the bean-shaped cross section, port E10, and in the port in the triangular cross section T10. A removable mirror in the ECRH tower which enables switching between two different CTS views is shown, as well as a port plug-in for the CTS view in the triangular cross section. (b) A closer look at the E10 port launcher/receiver antennas. Beam paths for the probing beams (red) and receiver beam (blue) are indicated. (c) A photograph of the in-vessel launching and receiving mirrors for the CTS view in the bean-shaped cross section.

ECRH and CTS beams are again split into the individual transmission lines; see Fig. 7(a). From the beam combining optics, the receiver beam travels in the single-beam section of the 


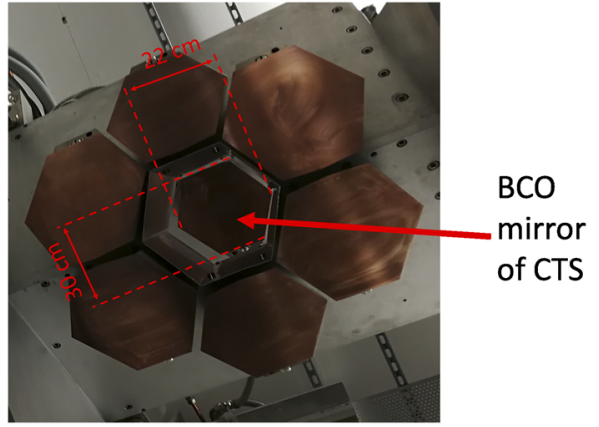

(a)

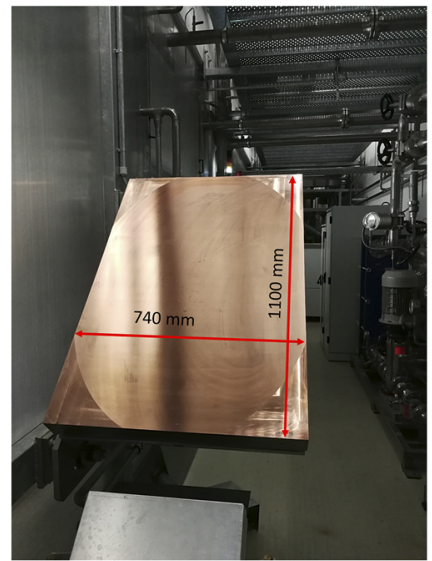

(b)

FIG. 7. Some mirrors in the quasi-optical transmission line. (a) Beam combining optics collects radiation from all the sources in module 1 and directs it to the multi-beam part of the transmission line. The received CTS beam (traveling in the opposite direction) is selected from the multi-beam part of the transmission line and directed to the receiver. The mirror of the beam combining optics for the CTS transmission line is in the center. (b) The first mirror of the multi-beam part of the quasi-optical transmission line for module 1. It can transmit up to seven beams simultaneously.

transmission line, gets polarized on two polarizers, ${ }^{27}$ and is guided into the CTS receiver, which is located in the Faraday cage built for the foreseen F1 gyrotron and is separated by a
$40 \mathrm{~cm}$ thick concrete wall from the quasi-optical transmission line.

\section{B. Remote steering antenna}

A remote steering quasi-optical antenna is designed and manufactured for the CTS diagnostic in port T10 (triangular cross section). It is shown in Fig. 8. The confocal mirror system images the pivot point of the receiver beam near to the plasma onto the only steerable mirror, which is situated at ambient air pressure outside the vacuum window. Therefore, no movable parts are needed in vacuum. The steerable mirror allows beam steering in one plane only. The extreme positions of the beam and the mirror are shown in the figure. The antenna provides optical imaging from a location near the pivot point at the end of the antenna (marked as a red dot on the left side of the figure) to the center of the vacuum window of the port (red dot on the right side of the figure). The antenna has four focusing mirrors, five plane reflectors, and a steerable mirror. Such a complex construction is needed to close the gap between the cryostat and the plasma vessel.

The steerable mirror located outside of the plasma vacuum moves in the slotted link by a linear driver. It allows steering the receiver beam by $\pm 15^{\circ}$ in one dimension. The amount of the mode loss of the Gaussian beam depends on the steering angle. However, in the entire range of steering angles, the Gaussian mode purity exceeds $97 \%$. The material for vacuum window is fused silica because only the low-power microwave beam is transmitted through it.

Prior to its installation at W7-X, the remote steering antenna was tested in the laboratory using a low-power microwave source. The transmitted beam quality as well as the steering capabilities was found to be in agreement with the design.

The CTS diagnostic is designed to run in steady-state plasmas of W7-X which last for $30 \mathrm{~min}$. This implies that the CTS antenna plug-in in the T10 port needs active cooling. The other receiver mirror location was already designed to have active cooling as it is part of the ECRH launcher. In the case of a receiver mirror in the triangular cross section, the main heating source is stray radiation from the injected

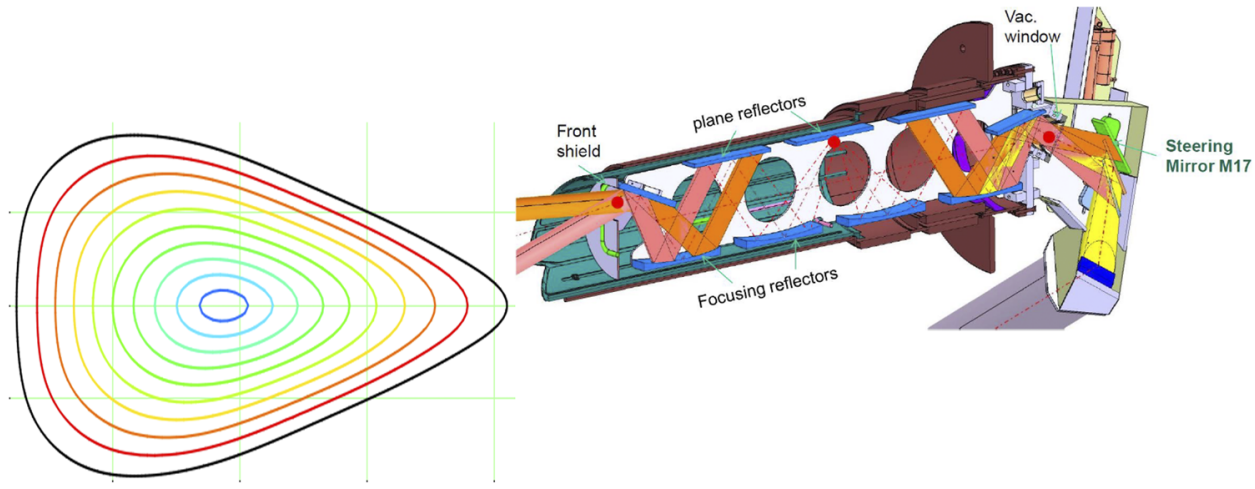

FIG. 8. A closer look at the port plug-in for the CTS view in a triangular cross section. A remote steering concept is implemented: the only movable mirror is located in ambient air and couples microwaves from the plug-in further into the transmission line. The steerable mirror is shown at its extreme steering positions. The two beams on the graph are both receiver beams at the extreme positions of the movable mirror and demonstrate the beam steering capabilities of the plug-in. 


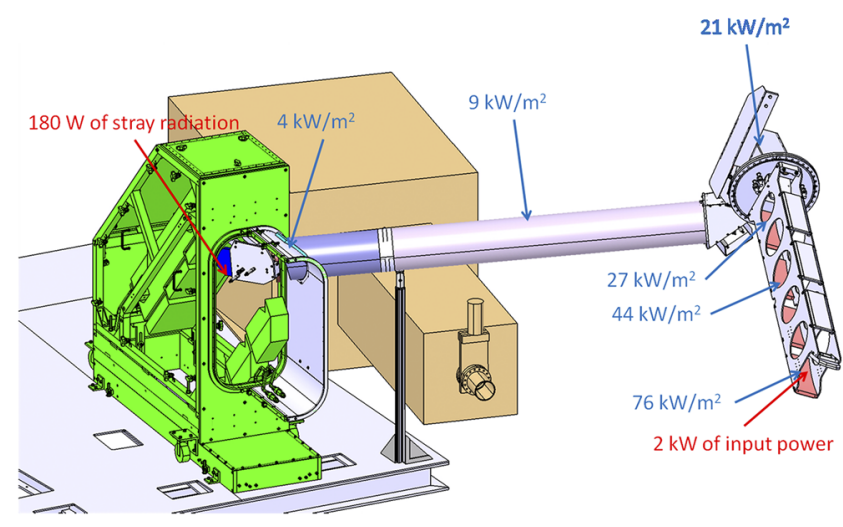

FIG. 9. The distribution of stray radiation in the transmission line from the port plug-in in the triangular cross section to the ECRH tower.

microwaves. In order to investigate where most of the stray radiation is absorbed, a dedicated analysis is conducted. In the worst case scenario, when $10 \%$ of the entire gyrotron power is not absorbed and bounces in the vessel, referred to as stray radiation, the antenna plug-in receives around $2 \mathrm{~kW}$ of microwave stray radiation. Stray radiation from ECE is not taken into account because of its insignificance in the W7-X plasmas. ${ }^{28}$ The distribution of stray radiation in the port plugin and in the transmission line from the port in the triangular cross section to the ECRH tower in module 1 is calculated using a multicavity model. ${ }^{29}$ The model has proven its validity in the OP1.1 campaign ${ }^{30}$ and is used to simulate the stray radiation loads in ITER. The distribution is shown in Fig. 9. The modeling shows that less than $10 \%$ of the input power, $180 \mathrm{~W}$ out of $2 \mathrm{~kW}$, will be transmitted into the ECRH tower which has an absorbing wall capable of dissipating orders of magnitude more. Most of the power, approximately $75 \%$, is expected to be absorbed in the plug-in. The analysis shows that for the steady-state operation, the plug-in has to be actively cooled, which unfortunately made the design of the plug-in more complicated. In the current experimental campaign, no steady-state operation is planned and active cooling is not necessary: the total injected energy into the plasma is not allowed to exceed $80 \mathrm{MJ}$ per discharge, which corresponds to about $10 \mathrm{~s}$ of operation at full ECRH power. In this case, the total energy that might enter the port plug-in as stray radiation is not more than $20 \mathrm{~kJ}$ which will not overheat the components.

Additionally, the remote steering antenna will be exposed to plasma radiation with intensities up to $100 \mathrm{~kW} / \mathrm{m}^{2}$. Therefore a heat shield and a port liner will be installed for the following experimental campaigns where Wendelstein 7-X will be operated in a steady-state regime.

\section{CTS receiver}

The CTS receiver at $\mathrm{W} 7-\mathrm{X}$ is a heterodyne radiometer and is installed in a gyrotron cage outside of the torus hall and the ECRH transmission lines. The design is similar to the one installed on ASDEX Upgrade and previously on TEXTOR.6,31,32
The receiver is equipped with a 16 channel filter bank for commissioning covering the frequency range 135-145 GHz, and a fast analog-to-digital converter (ADC), National Instruments model PXIe-5186, with a sampling rate of 6.25 (max. 12.5) Gsamples per second and a bandwidth of $5 \mathrm{GHz}$.

\section{ALIGNMENT OF THE TRANSMISSION LINE}

The alignment of the transmission line is crucial for the successful operation of the diagnostic since the measured signal originates from the overlap region between the probing and the receiver beams. Moreover, in the quasi-optical transmission line, a misalignment between the mirrors may lead to a total loss of the beam in severe cases, i.e., the received signal would not originate from the plasma at all.

The alignment procedure consists of two methodologically different tasks: aligning the mirrors of the transmission line so that the microwave (Gaussian) beam may travel from the receiver to the last mirror of the transmission line and, second, mapping the motor position of the steerable mirror onto the receiver beam trajectory in the vacuum vessel.

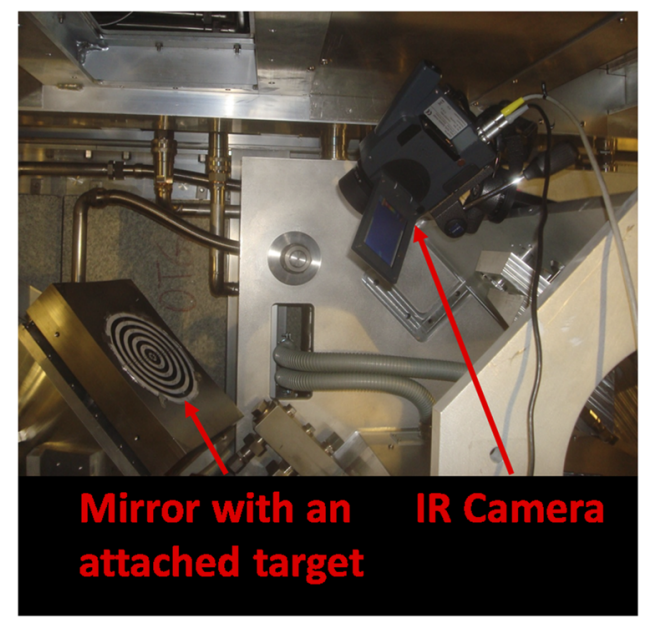

(a)

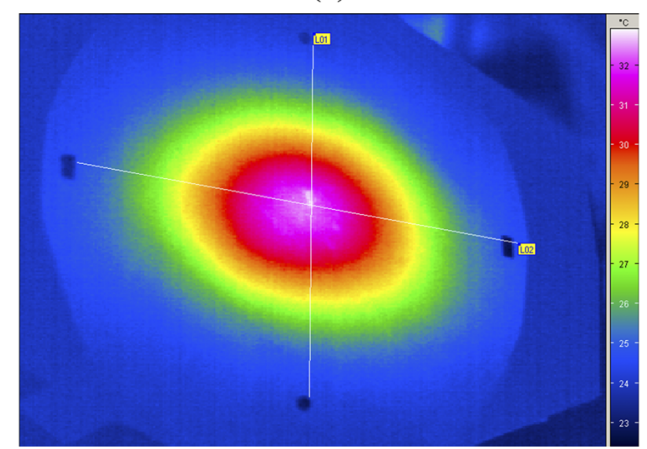

(b)

FIG. 10. (a) An example of the microwave alignment setup at mirror M13 of the CTS receiver transmission line; (b) an infrared image of the microwave beam on mirror M4 after adjustment of the previous mirror M3Z4. 

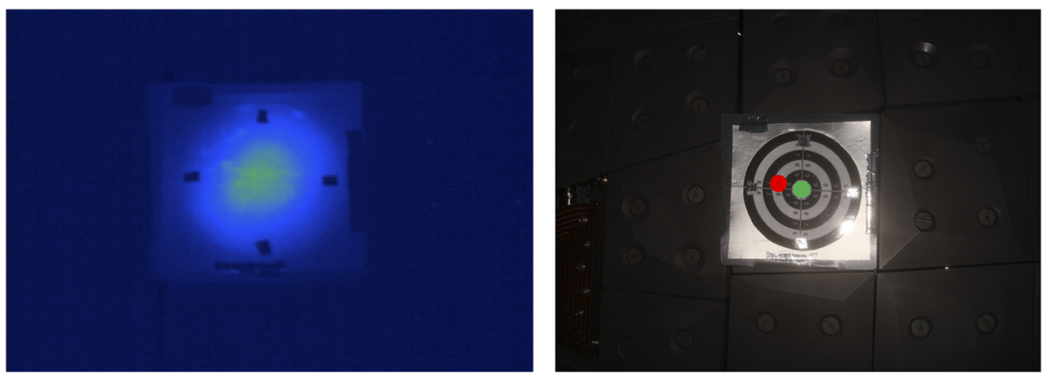

- Point according to the laser alignment

- Center of the measured mm-wave beam

The microwave alignment of the transmission line is performed by means of thermography. A $10 \mathrm{~W}$ microwave source (an extended interaction oscillator) is connected to the horn of the receiver so that the receiver becomes a transmitter. A microwave target, made of a wet laminated paper with glued reflective aluminum foil markers, is fixed at the center of the

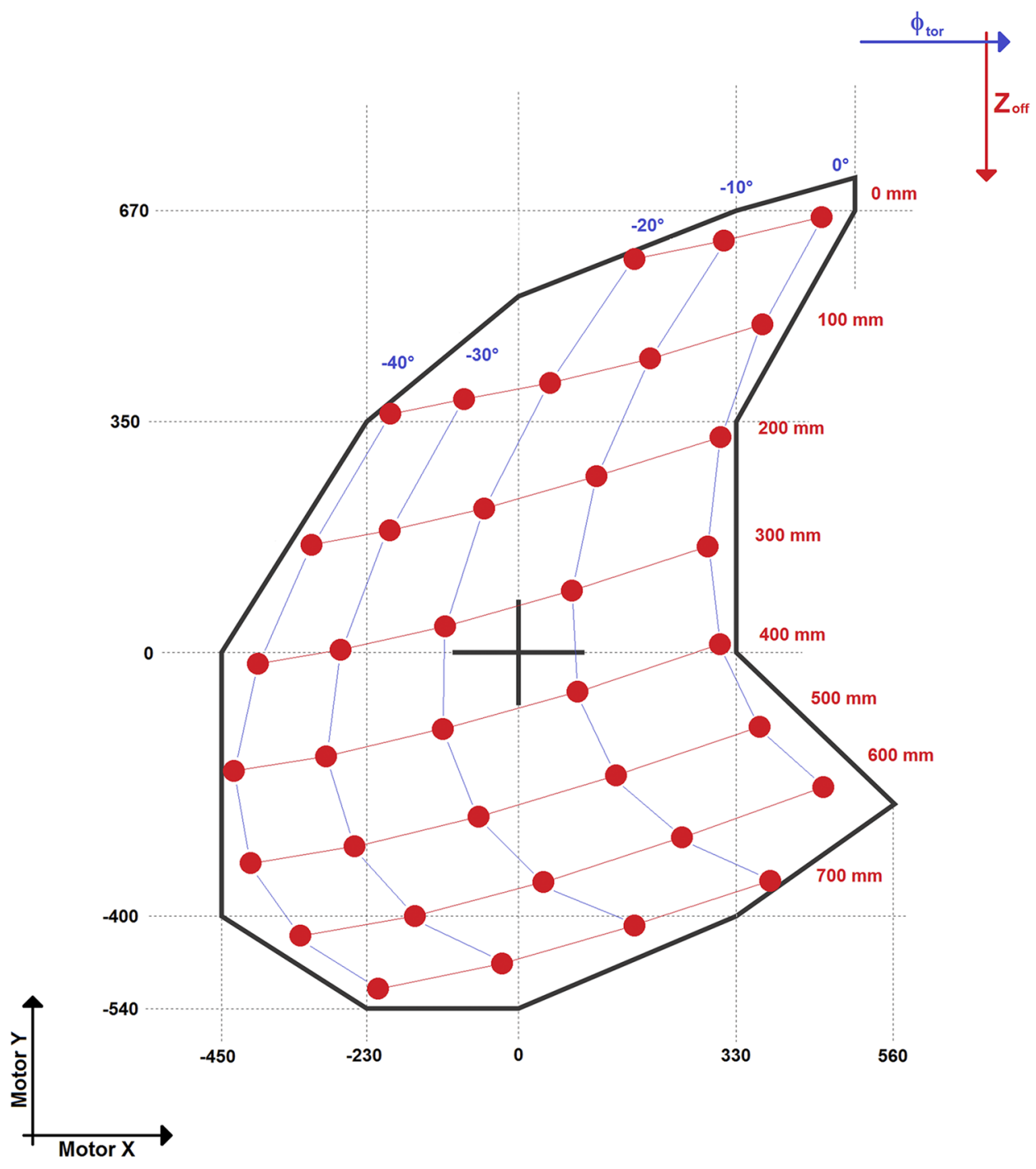

FIG. 12. A mapping between the motor drive positions $X$ and $Y$ of the steerable mirror of the CTS receiver in the beanshaped cross section to the beam-aiming parameters $\phi_{\text {tor }}$ and $Z_{\text {off }}$. The black solid line shows the operational limits of the steerable mirror.

FIG. 11. Comparison of the laser alignment with the microwave alignment. (left) An infrared image of the microwave beam on the target on a high-field-side wall. measurements (green dot) and the expected position of the beam center, calculated from the laser alignment (red dot) over-plotted on the wet-paper target on the high-field-side wall, the same as on the left panel. The reflective markers on the target are located $50 \mathrm{~mm}$ from the center of the target. 
first mirror. The beam pattern on the target is measured by an infrared camera monitoring the thermal footprint of the beam. The mirror is shifted in such a way that the beam is centered. When performed, the microwave target is fixed on the next mirror and the previous mirror is tilted around the normal to its surface, originating in the center of the beam so that the beam is centered on the next mirror. This procedure continues step by step from the first to the last mirror in the transmission line, except for the pre-aligned multi-beam section of the transmission line; see Fig. 5. However, the mirrors of the multi-beam transmission line did not need to be aligned specifically for CTS since it has already been aligned for the ECRH system. Generally, the multi-beam part of the transmission line needs to be aligned for two beams only and it becomes automatically aligned for all other beams transmitted through it (in total up to seven beams). An example of an alignment setup is shown in Fig. 10(a). An example of a thermographic measurement of the microwave beam on a wet-paper target is shown in Fig. 10(b).

The in-vessel alignment is performed by means of a double-sided laser beam. Small optical reflectors are installed in the centers of the last two microwave mirrors, and a semitransparent target is mounted on the vacuum window. The laser is installed inside the vacuum vessel in such a way that its beam, after being reflected from the reflectors on the microwave mirrors, meets the center of the vacuum window. Since the laser is double-sided, the interception point of the second beam on the high-field-side wall is recorded. Therefore, the motor positions of the mirror drive are mapped to the launching (or receiving) directions of the microwave beam. These mappings are performed for all ten launchers in the bean-shaped cross sections. The laser mapping is checked by the in-vessel microwave alignment at eleven different locations, when the microwave target is placed on the high-fieldside wall. It shows that the laser mapping technique is adequately suited for the aiming of the microwave beam; see Fig. 11 as an example.

Figure 12 shows the obtained mapping between the motor drive positions of the last steerable mirror in the CTS transmission line in the E10 port (bean-shaped cross section) to the beam-aiming parameters: the projection angle of the beam onto the equatorial plane to the normal to the magnetic axis $\left(\phi_{\text {tor }},{ }^{\circ}\right)$ and the vertical displacement of the microwave beam with respect to the magnetic axis $\left(\mathrm{Z}_{\text {off }}, \mathrm{mm}\right)$.

The CTS receiver mirror in the triangular cross section (T10 port) is capable of 1D motion only. Therefore the laser alignment is omitted.

\section{COMMISSIONING OF THE DIAGNOSTIC}

The diagnostic was commissioned in the bean-shaped and triangular cross sections. Here we present the first measurement results.

The scattering signal comes into the receiver from an overlap volume of the probing and receiver beams. To establish the location of the overlap of the probe and receiver

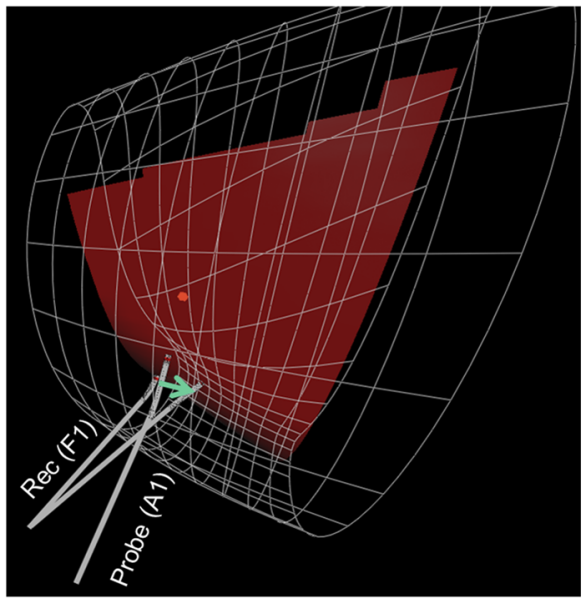

(a)

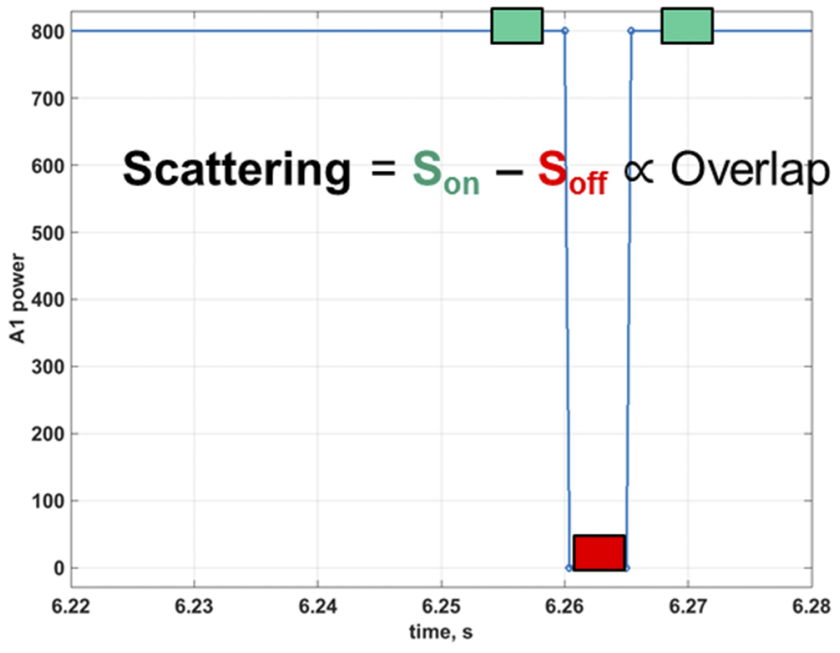

(b)

FIG. 13. (a) A sketch of the overlap sweep where the receiver beam is moved across the probing beam. A meshed surface illustrates the last closed flux surface, and the red surface is a cold second harmonic resonance surface for $140 \mathrm{GHz}$. (b) A modulation scheme of the probing gyrotron: for proper background subtraction, the gyrotron power is modulated between 0 and $800 \mathrm{~kW}$ with a duty cycle of $11 / 12$ and a period of $60 \mathrm{~ms}$.

beams, the receiver beam is swept across the probing beam, as shown in Fig. 13(a). This is a so-called overlap sweep. ${ }^{33}$ The sketch shows the receiver and probing beams, the last closed flux surface (as white mesh), and the cold resonance surface for $140 \mathrm{GHz}$ where the probing beam is absorbed. The probing beam is modulated with a duty cycle of $11 / 12$ and a period of $60 \mathrm{~ms}$ in order to allow background subtraction, as shown in Fig. 13(b).

\section{A. Commissioning in the bean-shaped cross section}

The average spectral power density during the overlap sweep is shown as a function of the launcher mirror angle of 


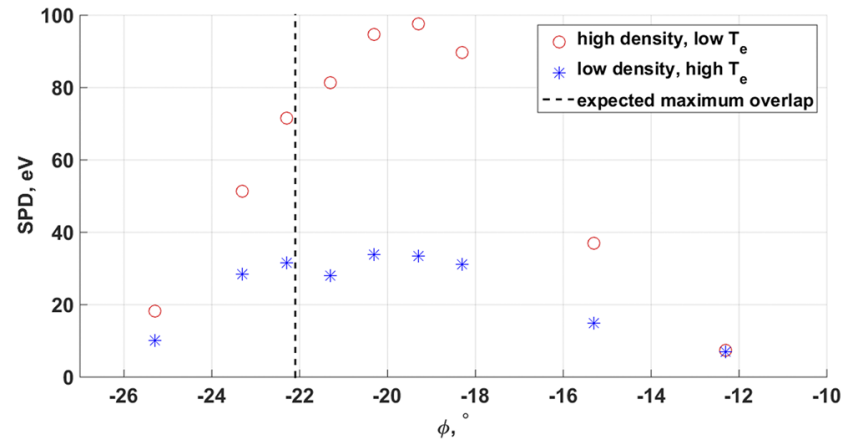

FIG. 14. Averaged SPD of the scattering signal as a function of the F1 launcher angle. The black dotted line shows where maximum overlap is expected according to ray-tracing. Red circles indicate measurements in the high density and low electron temperature phase of a discharge. Blue stars show measurements in the low density and high temperature phase of a discharge.

the receiver in Fig. 14. The averaging is performed in a frequency range from 139.85 to $139.95 \mathrm{GHz}$ and temporally over $70 \mathrm{~ms}$. Both the receiver and the probe worked in the X-mode. The mirror was moved on a shot-by-shot basis in a series of reproducible discharges in helium plasmas $20171011.049-$ 20171011.057. Blue star markers show the averaged spectral power density (SPD) in the low density and high $\mathrm{T}_{e}$ phase of the discharges whereas red circles show the high density and low $\mathrm{T}_{e}$ phase of the discharges. The SPD is not only proportional to the quality of the beam overlap but also to proportional the electron density. The less clearly defined bell shape of the overlap curve at lower density is also due to the poorer signal-to-noise ratio at higher levels of the background. ${ }^{34}$ The maximum overlap is found at the F1 aiming angle $19^{\circ}-20^{\circ}$, whereas the theoretically expected overlap is at $22^{\circ}$. Deviations of this magnitude are reasonable and can be explained by refraction.

The timetraces of one of the discharges from the series are shown in Fig. 15. The radiative central electron
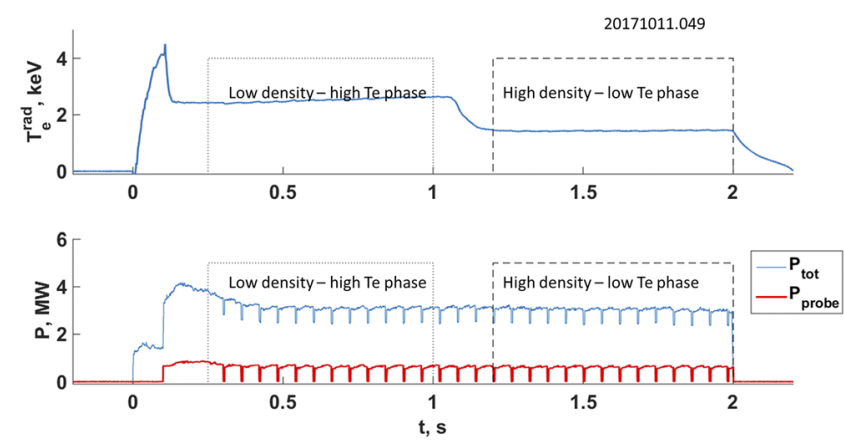

FIG. 15. Upper panel: radiative central electron temperature (channel 17 of the ECE radiometer). The dotted box indicates the low density and high $T_{e}$ period where the CTS data were acquired, $70 \mathrm{~ms}$ in total. The dashed box indicates the high density and low $T_{e}$ period where the CTS data were acquired, $70 \mathrm{~ms}$ in total. Lower panel: time traces of the total ECRH power (thin blue lines) and of the probing gyrotron $\mathrm{A} 1$ (thick red line).

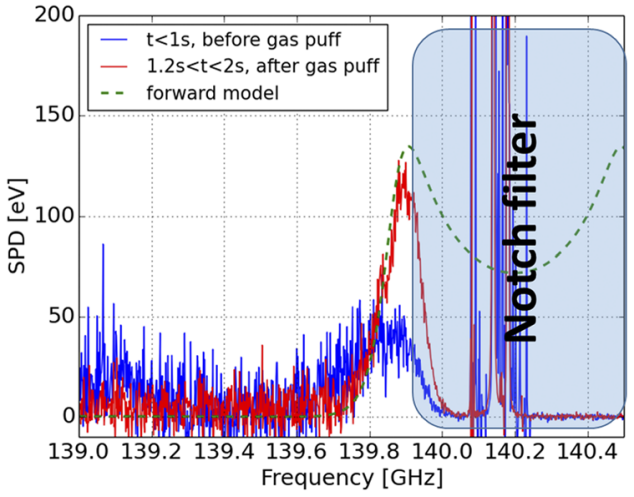

FIG. 16. Two CTS spectra: in the low density and high electron temperature phase of the discharge 20171011.053 (blue curve) and in the high density and low electron temperature phase of the same discharge (red curve). The green dotted line shows a fitted spectrum for the high-density phase of the discharge.

temperature is shown in the upper panel. After the $150 \mathrm{~ms}$ start-up phase, the discharge enters a stationary phase for $850 \mathrm{~ms}$. At $1 \mathrm{~s}$, an additional gas puff increases plasma density and, keeping heating constant, decreases the temperature until the discharge enters a second stationary phase at $1.2 \mathrm{~s}$. This decrease takes place over a confinement time scale, and at $1.2 \mathrm{~s}$, the discharge enters the second stationary phase for $800 \mathrm{~ms}$. At $2 \mathrm{~s}$, the discharge is terminated. A dotted box in Fig. 15 shows the period across which $70 \mathrm{~ms}$ of data for the low density and high electron temperature phase is acquired. A dashed box in Fig. 15 shows when the data for high density and low electron temperature are acquired. Unfortunately, no density measurements for these discharges are available. The lower panel shows time traces of the total ECRH power (thin blue line) and the power of the probing gyrotron A1 (thick red line).

Scattering spectra from the discharge 20171011.053 are displayed in Fig. 16. These spectra are averaged over $70 \mathrm{~ms}$, with the total acquisition periods extending over $800 \mathrm{~ms}$ of the corresponding plasma discharge period. In this discharge, two curves are shown for low and high density phases. The average magnetic field in the overlap region is $2.34 \mathrm{~T}$ at toroidal normalized flux $\rho_{t}=0.6$, the scattering angle $\theta=140^{\circ}$, and the angle between $k^{\delta}$ and the magnetic field is $109^{\circ}$. Based on these data, measured plasma parameters, and forward modeling using the eCTS code, ${ }^{23}$ a spectrum from the high density phase is shown along with the best-fit model spectrum. The fitted ion temperature is $1.2 \mathrm{keV}$. This is in reasonable agreement with the ion temperature measurements from the X-ray spectroscopy which measured in the same discharge but more centrally at $\rho_{t}=0.5$ is $1.4 \mathrm{keV}$.

\section{B. Commissioning in the triangular cross section}

The measurements were performed in the $77 \mathrm{~s}$ long hydrogen discharge 20181017.017 . There plasma parameters were constant throughout the discharge: central electron temperature $\mathrm{T}_{e}=2.7 \mathrm{keV}$, line integrated density $\mathrm{n}_{e}=5$ $\times 10^{19} \mathrm{~m}^{-2}$. The B1 gyrotron was launched in the $\mathrm{X}$ mode, 

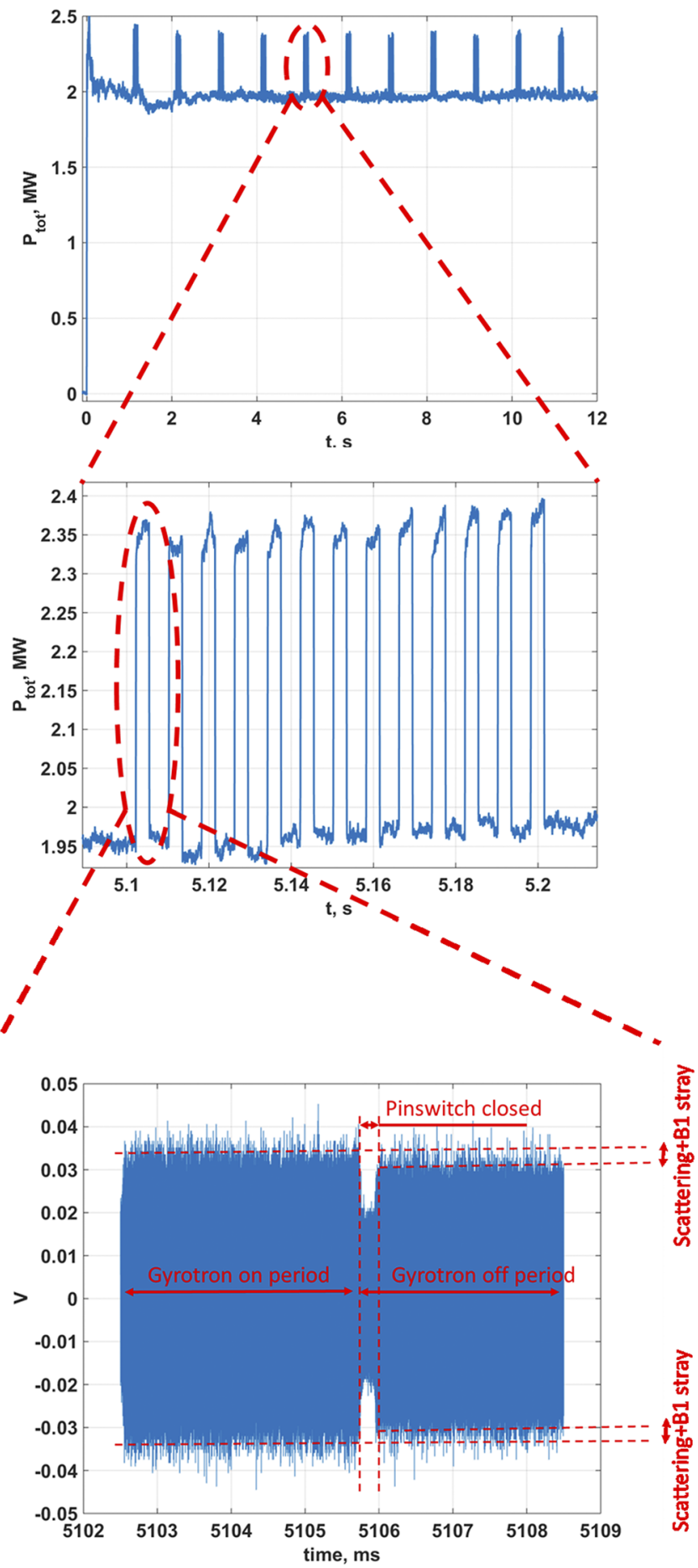

FIG. 17. Upper panel: time trace of the total heating power of the discharge 20181017.017 in the first $12 \mathrm{~s}$. Power modulations of the probing gyrotron are visible. Middle panel: zoomed view on the total heating power time trace. Lower panel: raw $A D C$ readings of one of the gyrotron bursts and with ECE background. and its power was modulated with the duty cycle of $44 \%$ and a frequency of $12.5 \mathrm{~Hz}$. The modulation was grouped into sequences, and each sequence consisted of 13 gyrotron bursts. The repetition rate of the burst sequences was $1 \mathrm{~Hz}$; see Fig. 17. One can clearly see power modulations of the probing gyrotron, the lower panel shows the corresponding raw signal acquired by the receiver's ADC of one of the gyrotron bursts. The difference in the signal level between the gyrotron-on and gyrotron-off periods is pronounced. This difference is attributed to both scattering and change in the stray radiation level of the probing gyrotron.

In order to state conclusively that we see scattering, an overlap sweep was performed, similar to what was performed in the bean-shaped cross section. Between each gyrotron burst sequence in the discharge 20181017.017, the probing beam was moved by $1^{\circ}$, therefore RSL1 performed a scan from

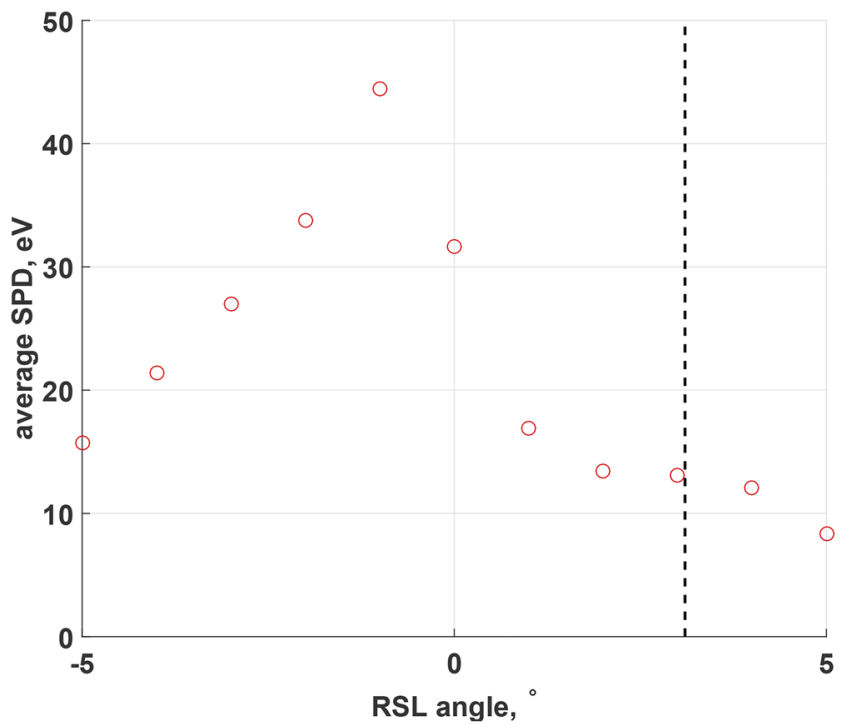

(a)

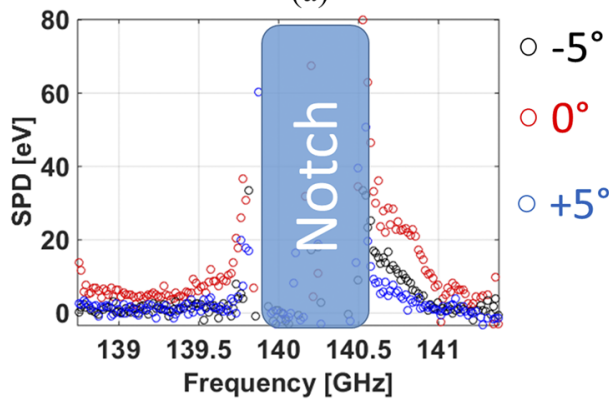

(b)

FIG. 18. (a) Averaged SPD of the scattering signal as a function of the RSL1 angle. The black dotted line shows where maximum overlap is expected according to ray-tracing. Red circles indicate measurements of the average scattering SPD in the frequency range from $141.55 \mathrm{GHz}$ to $142 \mathrm{GHz}$. (b) Three scattering spectra at different RSL1 angles: black circles at $-5^{\circ}$, blue circles at $+5^{\circ}$, and red circles at $0^{\circ}$. 
$-5^{\circ}$ to $+5^{\circ}$. The receiver beam was set to $-7^{\circ}$, and the receiver polarizers were set to the $\mathrm{X}$ mode. The results are displayed in Fig. 18(a). The figure shows an average scattering signal in the frequency range from $141.55 \mathrm{GHz}$ to $142.2 \mathrm{GHz}$. The overlap volume is placed in the plasma center at $\rho_{t}=0.05$. The black dotted line shows a theoretically expected angle of RSL1, where maximum overlap is expected. The discrepancy is, most likely, a combined effect of refraction and a small misalignment. For the given launcher and receiver geometry and polarization, refraction of the beams is significant. Three absolutely calibrated CTS spectra are shown in Fig. 18(b) for $-5^{\circ}, 0^{\circ}$, and $+5^{\circ}$ of the RSL1 angle. The analysis of the spectra is ongoing.

\section{CONCLUSIONS}

A CTS diagnostic for ion temperature measurements has been designed and installed on W7-X. The diagnostic features a highly sensitive, high-resolution heterodyne receiver. A heating gyrotron at $140 \mathrm{GHz}$ is the source of the probing radiation. The CTS receiver beam is transmitted to the receiver using the shared quasi-optical transmission line with the ECRH gyrotrons from module 1, including its own probing beam.

The diagnostic has two viewing locations in the cross sections with different magnetic topologies. In the triangular cross section, the plasma center is available for measurements. In the bean-shaped cross section at the standard magnetic field, the plasma center is unavailable due to the presence of the cold $140 \mathrm{GHz}$ ECE resonance. The resolution in the flux-surface co-ordinates in the triangular cross section is generally better in comparison with the bean-shaped cross section due to the different magnetic field topology. The exact values of achievable flux coordinate resolution depend on the exact geometry settings and chosen cross section and range from $\Delta \rho_{\mathrm{t}} \approx 0.1$ to $\Delta \rho_{\mathrm{t}} \approx 0.5$.

The receiver beam in the triangular-shaped cross section does not cross the ECE resonance layer on the first pass; one might expect a low level of the received ECE background. However, due to the highly reflecting walls of the vacuum vessel, a relatively high multi-pass ECE background is received.

The diagnostic has been commissioned in the beanshaped and triangular cross sections. Overlap sweeps are performed, and a deviation of position of the observed maximum from the expected maximum of the overlap is around $3^{\circ}-4^{\circ}$ both in the bean-shaped and triangular cross sections. This confirms a good quality of alignment. The first spectra in the bean-shaped cross section have been obtained and fitted by the eCTS code. The extracted ion temperature is in reasonable agreement with the ion temperature measured by X-ray spectroscopy.

\section{ACKNOWLEDGMENTS}

This work has been carried out within the framework of the EUROfusion Consortium and has received funding from the Euratom research and training programme 2014-2018 under Grant Agreement No. 633053. The views and opinions expressed herein do not necessarily reflect those of the European Commission.

\section{REFERENCES}

${ }^{1}$ N. A. Pablant, M. Bitter, R. Burhenn, L. Delgado-Aparicio, R. Ellis, D. Gates, M. Goto, K. W. Hill, A. Langenberg, S. Lazerson, M. Mardenfeld, S. Morita, G. H. Neilson, T. Oishi, and T. S. Pedersen, in 41st EPS Conference on Plasma Physics (European Physical Society, Berlin, Germany, 2014), p. P1.076.

${ }^{2}$ N. A. Pablant, R. E. Bell, M. Bitter, L. Delgado-Aparicio, K. W. Hill, S. Lazerson, and S. Morita, Rev. Sci. Instrum. 85, 11E424 (2014).

${ }^{3}$ N. A. Pablant, M. Bitter, L. Delgado-Aparicio, M. Goto, K. W. Hill, S. Lazerson, S. Morita, A. L. Roquemore, D. Gates, D. Monticello, H. Nielson, A. Reiman, M. Reinke, J. E. Rice, and H. Yamada, Rev. Sci. Instrum. 83, 083506 (2012)

${ }^{4}$ F. Meo, H. Bindslev, S. B. Korsholm, V. Furtula, F. Leuterer, F. Leipold, P. K. Michelsen, S. K. Nielsen, M. Salewski, J. Stober, D. Wagner, and P. Woskov, Rev. Sci. Instrum. 79, 10E501 (2008).

${ }^{5}$ M. Salewski, F. Meo, M. Stejner, O. Asunta, H. Bindslev, V. Furtula, S. B. Korsholm, T. Kurki-Suonio, F. Leipold, F. Leuterer, P. K. Michelsen, D. Moseev, S. K. Nielsen, J. Stober, G. Tardini, D. Wagner, and P. Woskov, Nucl. Fusion 50, 035012 (2010).

${ }^{6}$ V. Furtula, M. Salewski, F. Leipold, P. K. Michelsen, S. B. Korsholm, F. Meo, D. Moseev, S. K. Nielsen, M. Stejner, and T. Johansen, Rev. Sci. Instrum. 83, 013507 (2012).

${ }^{7}$ J. Rasmussen, S. K. Nielsen, M. Stejner, B. Geiger, M. Salewski, A. S. Jacobsen, S. B. Korsholm, F. Leipold, P. K. Michelsen, D. Moseev, M. Schubert, J. Stober, G. Tardini, and D. Wagner, Plasma Phys. Controlled Fusion 57, 075014 (2015)

${ }^{8}$ S. K. Nielsen, M. Stejner, J. Rasmussen, A. S. Jacobsen, S. B. Korsholm, F. Leipold, M. Maraschek, F. Meo, P. K. Michelsen, D. Moseev, M. Salewski, M. Schubert, J. Stober, W. Suttrop, G. Tardini, and D. Wagner, Plasma Phys. Controlled Fusion 57, 035009 (2015).

${ }^{9}$ M. Stejner, S. K. Nielsen, A. S. Jacobsen, S. B. Korsholm, F. Leipold, R. M. McDermott, P. K. Michelsen, J. Rasmussen, M. Salewski, M. Schubert, J. Stober, and D. H. Wagner, Plasma Phys. Controlled Fusion 57, 062001 (2015).

${ }^{10}$ M. Stejner, M. Salewski, S. B. Korsholm, H. Bindslev, E. Delabie, F. Leipold, F. Meo, P. K. Michelsen, D. Moseev, S. K. Nielsen, A. Bürger, and M. de Baar, Plasma Phys. Controlled Fusion 55, 085002 (2013).

${ }^{11}$ M. Stejner, S. Nielsen, A. S. Jacobsen, S. B. Korsholm, F. Leipold, F. Meo, P. K. Michelsen, D. Moseev, J. Rasmussen, M. Salewski, M. Schubert, J. Stober, and D. H. Wagner, Rev. Sci. Instrum. 85, 093504 (2014).

${ }^{12}$ M. Nishiura, S. Kubo, K. Tanaka, R. Seki, S. Ogasawara, T. Shimozuma, K. Okada, S. Kobayashi, T. Mutoh, K. Kawahata, T. Watari, T. Saito, Y. Tatematsu, S. Korsholm, and M. Salewski, Nucl. Fusion 54, 023006 (2014).

${ }^{13}$ E. V. Suvorov, V. Erckmann, E. Holzhauer, W. Kasparek, Y. A. Dryagin, S. E. Fil'chenkov, A. A. Fraiman, T. Geist, M. Kick, L. M. Kukin, A. V. Kostrov, L. V. Lubyako, A. M. Shtanyuk, N. K. Skalyga, and O. B. Smolyakova, Plasma Phys. Controlled Fusion 37, 1207 (1995).

${ }^{14}$ M. Salewski, O. Asunta, L.-G. Eriksson, H. Bindslev, V. Hynönen, S. B. Korsholm, T. Kurki-Suonio, F. Leipold, F. Meo, P. K. Michelsen, S. K. Nielsen, and J. Roenby, Plasma Phys. Controlled Fusion 51, 035006 (2009).

${ }^{15}$ M. Salewski, S. K. Nielsen, H. Bindslev, V. Furtula, N. N. Gorelenkov, S. B. Korsholm, F. Leipold, F. Meo, P. K. Michelsen, D. Moseev, and M. Stejner, Nucl. Fusion 51, 083014 (2011).

${ }^{16}$ D. Moseev, M. Salewski, M. Garcia-Muñoz et al., Rev. Mod. Plasma Phys. (published online).

${ }^{17}$ M. Salewski, B. Geiger, A. Jacobsen, I. Abramovic, S. Korsholm, F. Leipold, B. Madsen, J. Madsen, R. McDermott, D. Moseev, S. Nielsen, M. Nocente, J. Rasmussen, M. Stejner, M. Weiland, TEM Team, and TAU Team, Nucl. Fusion 58, 036017 (2018). 
${ }^{18}$ M. Stejner, J. Rasmussen, S. Nielsen, A. Jacobsen, S. B. Korsholm, F. Leipold, R. M. McDermott, M. Salewski, M. Schubert, J. Stober, and D. Wagner, Plasma Phys. Controlled Fusion 59, 075009 (2017).

${ }^{19}$ M. Stejner, S. Nielsen, A. Jacobsen, S. Korsholm, and F. Leipold, "Measuring main-ion temperatures in ASDEX Upgrade using scattering of ECRH radiation," in 41st International Conference on Infrared, Milimeter, and Terahert Waves (IEEE, Copenhagen, Denmark, 2016).

${ }^{20}$ E. E. Salpeter, Phys. Rev. 120, 1528 (1960).

${ }^{21}$ H. Bindslev, J. Atmos. Terr. Phys. 58, 983 (1996).

22 J. Svensson, O. Ford, D. McDonald, A. Meakins, A. Werner, M. Brix, A. Boboc, M. Beurskens, and JET EFDA Contributors, Contrib. Plasma Phys. 51, 152 (2011).

${ }^{23}$ I. Abramovic, A. Pavone, D. Moseev, N. Lopes Cardozo, M. Salewski, and H. Laqua, Rev. Sci. Instrum. (submitted).

${ }^{24}$ J. van den Berg, I. Abramovic, N. Lopes Cardozo, and D. Moseev, Rev. Sci. Instrum. 89, 083507 (2018).

${ }^{25}$ V. Erckmann, P. Brand, H. Braune, G. Dammertz, G. Gantenbein, W. Kasparek, H. P. Laqua, H. Maassberg, N. B. Marushchenko, G. Michel, M. Thumm, Y. Turkin, M. Weissgerber, and A. Weller, Fusion Sci. Technol. 52, 291 (2007).

${ }^{26}$ V. Erckmann, P. Brand, H. Braune, G. Dammertz, G. Gantenbein, W. Kasparek, H. P. Laqua, G. Michel, M. Thumm, and M. Weissgerber, in Fusion Energy 2006 (International Atomic Energy Agency, Chengdu, 2007), pp. IT/2-4Rd.
${ }^{27}$ G. Michel, V. Erckmann, F. Hollmann, L. Jonitz, W. Kasparek, H. Laqua, C. Lechte, N. Marushchenko, B. Plaum, Y. Turkin, and M. Weißgerber, Fusion Eng. Des. 88, 903 (2013).

${ }^{28}$ D. Moseev, H. P. Laqua, S. Marsen, T. Stange, H. Braune, V. Erckmann, F. Gellert, and J. W. Oosterbeek, Rev. Sci. Instrum. 87, 083505 (2016).

${ }^{29}$ H. P. Laqua, V. Erckmann, and M. Hirsch, in 28th EPS Conference on Controlled Fusion and Plasma Physics (European Physical Society, June 2001), p. P3.099.

${ }^{30}$ D. Moseev, H. Laqua, S. Marsen, N. Marushchenko, T. Stange, H. Braune, F. Gellert, M. Hirsch, U. Hoefel, J. Knauer, J. Oosterbeek, Y. Turkin, and TWX Team, Nucl. Fusion 57, 036013 (2017).

${ }^{31}$ M. Stejner, S. K. Nielsen, S. B. Korsholm, M. Salewski, H. Bindslev, V. Furtula, F. Leipold, F. Meo, P. K. Michelsen, D. Moseev, A. Bürger, M. Kantor, and M. de Baar, Rev. Sci. Instrum. 81, 10D515 (2010).

${ }^{32}$ V. Furtula, F. Leipold, M. Salewski, P. K. Michelsen, S. B. Korsholm, F. Meo, D. Moseev, S. K. Nielsen, M. Stejner, and T. Johansen, J. Instrum. 7, C02039 (2012).

${ }^{33}$ S. K. Nielsen, H. Bindslev, L. Porte, J. A. Hoekzema, S. B. Korsholm, F. Leipold, F. Meo, P. K. Michelsen, S. Michelsen, J. W. Oosterbeek, E. L. Tsakadze, G. Van Wassenhove, E. Westerhof, and P. Woskov, Phys. Rev. E 77, 016407 (2008).

${ }^{34} \mathrm{H}$. Bindslev, "On the theory of Thomson scattering and reflectometry in a relativistic magnetized plasma," Ph.D. thesis, Ris $\emptyset$ National Laboratory, 1992. 